\section{Tradução e adaptação da escala Motorcycle Rider Behavior Questionnaire: versão brasileira}

\author{
Translation and adaptation of the Motorcycle Rider \\ Behavior Questionnaire: a Brazilian version
}

\author{
1 Programa de Pós-graduação \\ em Psicologia, Pontifícia \\ Universidade Católica do Rio \\ Grande do Sul, Porto Alegre, \\ Brasil. \\ 2 Faculdade de Medicina, \\ Universidade Luterana do \\ Brasil, Canoas, Brasil. \\ 3 Institute of Psychiatry, \\ King's College London, \\ London, UK \\ 4 Programa de Pós-graduação \\ em Psiquiatria, Universidade \\ Federal do Rio Grande do Sul, \\ Porto Alegre, Brasil. \\ 5 Hospital de Clínicas de \\ Porto Alegre, Universidade \\ Federal do Rio Grande do Sul, \\ Porto Alegre, Brasil. \\ 6 Programa de Pós-graduação \\ em Saúde Coletiva, \\ Universidade Luterana do \\ Brasil, Canoas, Brasil. \\ Correspondência \\ R. P. S. Coelho \\ Programa de Pós-graduação \\ em Psicologia, Pontifícia \\ Universidade Católica do Rio \\ Grande do Sul. \\ Av. Ipiranga 6681, prédio 11, \\ sala 936, Porto Alegre, RS \\ 90619-900, Brasil. \\ robertacoelho@terra.com.br
}

\section{Abstract}

Traffic accidents are a leading cause of death in young adults. In Brazil, traffic accidents are proportionally more prevalent among motorcyclists as compared to automobile drivers. Although numerous data indicate that individual characteristics are involved in traffic accident risk, there is no instrument in Brazil to assess motorcyclists' traffic behavior. The authors thus proposed to perform translation and cultural adaptation of the Motorcycle Rider Behavior Questionnaire (MRBQ) into Brazilian Portuguese. The translation process consisted of: two independent translations into Brazilian Portuguese; unification of the translations; back-translation into English; formal assessment of semantic equivalence; application of a summary version in a convenience sample of motorcyclists; generation of a final version; and back-translation and submission to the original author, who approved this version. The Brazilian version maintained its semantic equivalence and was accepted by the convenience sample, an important characteristic for a self-completed instrument. Further studies are necessary to evaluate the questionnaire's psychometric properties in the Brazilian cultural context.

Questionnaire; Translating; Traffic Accidents; Motorcycles

\author{
Roberta Paula Schell Coelho 1 \\ Rodrigo Grassi-Oliveira ${ }^{1}$ \\ Mônica Machado 2 \\ Anna Virginia Williams 3 \\ Breno Córdova Matte 4 \\ Flavio Pechansky 5 \\ Luis Augusto Paim Rohde 5 \\ Claudia Maciel Szobot 6
}

\section{Introdução}

Os acidentes de trânsito correspondem a uma importante preocupação de saúde pública em diversos países 1. De acordo com a Organização Mundial da Saúde (OMS), cerca de 1.200.000 mortes por acidentes de trânsito ocorrem anualmente e aproximadamente 3.500 pessoas morrem nas estradas do mundo a cada dia ${ }^{2}$. Algumas frações da população acabam sendo mais vulneráveis, como os pedestres, ciclistas e motociclistas 2 . Na última década, dentre os acidentes de trânsito, observou-se o aumento crescente do número de acidentes envolvendo motocicletas, por ser um veículo ágil e de custo reduzido $3,4,5$. No Brasil, o crescimento expressivo da frota de motocicletas está aliado à sua utilização nos serviços de entrega de mercadorias, podendo assim, contribuir para o aumento de acidentes envolvendo motociclistas 6 .

A relevância de investigarmos o comportamento no trânsito vem ficando evidente. São alarmantes as estatísticas reveladas sobre acidentes envolvendo motociclistas, resultando em sérios prejuízos e por vezes levando à morte. Trata-se de uma preocupação de saúde pública, ressaltando inclusive os elevados gastos públicos provenientes dessas estatísticas.

Apesar do perceptível aumento da prevalência de acidentes de trânsito com motociclistas no Brasil, não há um instrumento em português para avaliar o comportamento dessa população es- 
pecialmente vulnerável. No intuito de pesquisar qual seria a postura do motociclista que acaba se predispondo a um maior risco de acidentes, foi elaborado um questionário que se propõe a analisar o comportamento do motociclista no trânsito, assim como o uso de equipamentos de proteção ${ }^{3}$. O Motorcycle Rider Behavior Questionnaire (MRBQ) é um instrumento já empregado por autores de outros países para avaliar as atitudes e o estilo de dirigir dos motociclistas envolvidos em acidentes de trânsito ${ }^{3,7}$. A literatura nacional não apresenta estudos com instrumentação voltada para a população de motociclistas, sendo este um trabalho pioneiro. Devido à escassez de estudos na área, o MRBQ é o instrumento de referência mais atualizado, apresentando adequadas propriedades psicométricas. Este trabalho objetivou efetuar o processo de tradução e as etapas iniciais do processo de adaptação transcultural do MRBQ para o português brasileiro, considerando a equivalência conceitual de itens e semântica.

\section{Métodos}

Este trabalho integra um projeto amplo, de título Associação entre Acidentes de Trânsito por Motociclistas, Transtorno por Uso de Substâncias Psicoativas e Transtorno de Déficit de Atenção/Hiperatividade, aprovado pelo Comitê de Ética em Pesquisa do Hospital de Clínicas de Porto Alegre, sob o número 06-450.

Obteve-se autorização para desenvolver e utilizar a versão em português do MRBQ, a partir do seu autor, por meio de comunicação eletrônica. O processo de tradução e adaptação transcultural foi baseado nas diretrizes gerais do método proposto por Herdman et al. 8,9.

\section{Instrumento}

O MRBQ foi elaborado com base no Driving Behavior Questionnaire (DBQ), por Reason et al. 10. Foram selecionados itens da escala DBQ que possuíam relevância no estudo do comportamento dos motociclistas e criados novos itens específicos ao motociclismo, assim gerando a MRBQ. Essa escala foi originalmente desenvolvida no Reino Unido, na língua inglesa, e ainda não há publicações referindo tradução para outros idiomas.

O MRBQ possui 44 itens, sendo os dez primeiros acerca dos equipamentos de segurança utilizados pelos motociclistas, e os demais sobre o comportamento do motociclista no trânsito, bem como o nível de atenção ao dirigir ${ }^{3}$. Os itens podem ser divididos em cinco fatores: (1) erros no trânsito; (2) violação de velocidade; (3) acro- bacias; (4) uso de equipamentos de segurança; e (5) controle de erros. As respostas são referidas em uma escala com seis pontos de frequência: nunca, quase nunca, ocasionalmente, com alguma frequência, frequentemente e quase toda hora. O uso do MRBQ não necessita treinamento por ser um instrumento autoaplicável.

Em relação aos indicadores de validade de construto, Elliot et al. 3 utilizaram a análise dos componentes principais - rotação varimax - e indicaram uma estrutura de cinco fatores, explicando $41,2 \%$ da variância. A contribuição de cada um dos fatores foi equivalente, variando entre 10,3\% (erros no trânsito) e 7,5\% (uso de equipamentos de segurança). Em relação à fidedignidade, os índices de consistência interna variaram entre 0,87 e 0,70 (alpha de Cronbach) revelando adequadas propriedades psicométricas ${ }^{3}$.

\section{Procedimentos}

Foram realizadas oito etapas consecutivas. A etapa 1 consistiu em duas traduções da versão original (VO) do instrumento para o português, realizadas de forma independente. A primeira delas (T1) foi realizada por um psiquiatra proficiente e fluente em língua inglesa, e a segunda (T2) por um linguista com especialização no idioma inglês, ambos brasileiros. Nessa etapa, foram mantidas as características originais (equivalência operacional), o que resultou em uma maior confiabilidade e validade do instrumento. Na etapa 2, unificou-se as traduções T1 e T2, por intermédio de um comitê de juízes composto pelos autores e, havendo um consenso, gerou-se a versão 1 (V1). A etapa 3 consistiu na retrotradução (R1) da V1 para o inglês por um profissional bilíngue cuja língua nativa é o português. Na etapa 4, realizouse a apreciação formal de equivalência semântica por um linguista e por um psiquiatra. Para o julgamento da equivalência semântica foram avaliados pelos autores R.G.O. e R.P.S.C. o significado geral e referencial dos termos e das expressões de cada um dos 44 itens que compõem a escala. Os significados gerais representavam as ideias a que uma única palavra remetia. Os significados referenciais representaram a correspondência literal entre as palavras e expressões. Assim, na equivalência semântica levou-se em consideração, além do significado das palavras entre os dois idiomas diferentes, o efeito que estas palavras tinham em diferentes culturas. Na etapa 5, elaborou-se uma versão síntese com base no julgamento de cada um dos itens pelos autores, com base nas avaliações obtidas na etapa 4, gerando a versão 2 (V2). Na etapa 6, por meio de uma amostra de conveniência, realizou-se três grupos focais com cinco motociclistas cada um, para avaliar o entendi- 
mento e aceitabilidade dos itens da escala. Os 15 participantes foram solicitados a completar a V2 antes do início de cada grupo. Na etapa 7, discutiu-se os itens que apresentaram problemas de entendimento e aceitabilidade nesses grupos focais. Elaborou-se assim uma versão final (VF). A etapa 8 consistiu na retrotradução (R2) da VF e no seu envio para o autor original para sua apreciação.

\section{Resultados}

Houve discordância entre a tradução realizada pelo psiquiatra e pelo linguista (T1 e T2) em 21 itens das 51 (41,17\%) sentenças contidas em todo instrumento, incluindo instruções e as opções de respostas. Dentre os 21 itens discordantes, optou-se por seis sugestões propostas pelo T1 $(28,57 \%)$, e as demais $15(71,42 \%)$ por sugestões do T2. Exemplos dessas discordâncias estão ilustrados na Tabela 1 .

A discussão sobre a apreciação da equivalência semântica levou a ajustes linguísticos e adaptações terminológicas, com consequente elaboração de novas versões em 9 das 51 sentenças que compõem a escala $(17,64 \%)$. No grupo focal foram sugeridas modificações em 16 sentenças $(31,37 \%)$, com acréscimo, exclusão ou modificação de alguma palavra. Por exemplo, a questão 23, "Run wide when going round a corner", que ficou na V1 como: "Faz uma curva aberta quando contorna uma esquina"; após o grupo focal, optou-se por "Faz uma curva aberta quando dobra uma esquina”. A versão final, com as alterações do grupo focal, foi retrotraduzida para o inglês e enviada ao autor, que a aprovou. A escala ficou denominada de Escala de Comportamento no Trânsito para Motociclistas (ECTM) (Figura 1).

\section{Conclusões}

O presente estudo apresentou a tradução e avaliação da equivalência conceitual, semântica e de itens do MRBQ, que se mostrou uma ferramenta útil na investigação do comportamento de motociclistas, tanto como um instrumento de pesquisa mas também como mais um elemento auxiliar na avaliação desta população.

As etapas iniciais do processo de adaptação transcultural deste instrumento apresentaram uma limitação, pois foram desenvolvidas com base em uma amostra de conveniência com motoboys, que necessariamente não são representativos da cultura dos motociclistas como um todo. Motoboys utilizam motocicletas para a realização do seu trabalho diário. É possível que esse grupo utilize um vocabulário particular, talvez não conhecido por outros motociclistas. Espera-se que a etapa 7 tenha minimizado a inclusão de jargões utilizados por esse grupo na versão final da escala. No entanto, recomenda-se que essa escala seja aplicada em uma amostra mais ampla

Tabela 1

Exemplos de discordância entre as traduções 1, 2 e a versão 1.

\begin{tabular}{|c|c|c|c|}
\hline Versão original & Tradução 1 & Tradução 2 & Versão 1 \\
\hline Tick one box on each line & Marque uma caixa em cada linha & $\begin{array}{l}\text { Marque uma alternativa em cada } \\
\text { linha }\end{array}$ & $\begin{array}{l}\text { Marque uma alternativa em cada } \\
\text { linha }\end{array}$ \\
\hline Occasionally & Eventualmente & Ocasionalmente & Ocasionalmente \\
\hline $\begin{array}{l}\text { When riding, how often do each of } \\
\text { the following happen to you? }\end{array}$ & $\begin{array}{l}\text { Quando você está dirigindo, com } \\
\text { que frequência cada uma dessas } \\
\text { coisas acontece com você? }\end{array}$ & $\begin{array}{l}\text { Quando dirigindo, com que } \\
\text { frequência cada qual das seguintes } \\
\text { coisas acontecem com você? }\end{array}$ & $\begin{array}{l}\text { Quando você está dirigindo, com } \\
\text { que frequência cada uma dessas } \\
\text { coisas acontece com você? }\end{array}$ \\
\hline Wear a leather one-piece suit? & Usa um macacão de couro? & Veste um macacão de couro? & Usa um macacão de couro? \\
\hline $\begin{array}{l}\text { Wear a protective jacket (leather or } \\
\text { non leather)? }\end{array}$ & $\begin{array}{l}\text { Usa uma jaqueta de proteção (de } \\
\text { couro ou não)? }\end{array}$ & $\begin{array}{l}\text { Usa uma jaqueta de proteção } \\
\text { (couro ou outro material)? }\end{array}$ & $\begin{array}{l}\text { Usa uma jaqueta de proteção } \\
\text { (couro ou outro material)? }\end{array}$ \\
\hline $\begin{array}{l}\text { Use dipped headlights on your } \\
\text { bike? }\end{array}$ & Usa luz baixa na sua moto? & Usa farol baixo na sua moto? & Usa luz baixa na sua moto? \\
\hline $\begin{array}{l}\text { Pull out on to a main road in } \\
\text { front of a vehicle that you hadn't } \\
\text { noticed, or whose speed you have } \\
\text { misjudged }\end{array}$ & $\begin{array}{l}\text { Entra em uma via principal em } \\
\text { frente a um veículo que você não } \\
\text { havia notado, ou cuja velocidade } \\
\text { você não calculou }\end{array}$ & $\begin{array}{l}\text { Entra em uma rua na frente de um } \\
\text { veículo que você não tinha notado } \\
\text { ou cuja velocidade você tinha } \\
\text { calculado mal }\end{array}$ & $\begin{array}{l}\text { Entra em uma rua na frente de um } \\
\text { veículo que você não tinha notado } \\
\text { ou cuja velocidade você tinha } \\
\text { calculado mal }\end{array}$ \\
\hline
\end{tabular}


Figura 1

Escala de Comportamento no Trânsito para Motociclistas (ECTM).

\begin{tabular}{|c|c|c|c|c|c|c|c|}
\hline & & $\begin{array}{l}(1) \\
\text { Nunca }\end{array}$ & $\begin{array}{c}(2) \\
\text { Quase nunca }\end{array}$ & $\begin{array}{c}\text { (3) } \\
\text { Ocasionalmente }\end{array}$ & $\begin{array}{l}\text { (4) } \\
\text { Com alguma } \\
\text { frequência }\end{array}$ & $\begin{array}{l}(5) \\
\text { Frequentemente }\end{array}$ & $\begin{array}{c}(6) \\
\text { Quase toda hora }\end{array}$ \\
\hline \multicolumn{8}{|c|}{ Quando está dirigindo, com que frequência você: } \\
\hline 1. & Usa macacão de couro? & & & & & & \\
\hline 2. & Usa jaqueta de proteção (couro ou outro material)? & & & & & & \\
\hline 3. & Usa calça de proteção (couro ou outro material)? & & & & & & \\
\hline 4. & $\begin{array}{l}\text { Usa outros equipamentos de proteção } \\
\text { (para cotovelo, ombro, joelho etc.)? }\end{array}$ & & & & & & \\
\hline 5. & Usa botas para dirigir? & & & & & & \\
\hline 6. & Usa luvas? & & & & & & \\
\hline 7. & Usa roupas brilhantes ou fluorescentes? & & & & & & \\
\hline 8. & $\begin{array}{l}\text { Usa faixas ou adesivos brilhantes ou } \\
\text { fluorescentes nas suas roupas? }\end{array}$ & & & & & & \\
\hline 9. & Usa luz baixa na sua moto? & & & & & & \\
\hline 10. & $\begin{array}{l}\text { Tem problemas porque sua viseira ou óculos } \\
\text { de proteçãa ficam embaçados? }\end{array}$ & & & & & & \\
\hline \multicolumn{8}{|c|}{$\begin{array}{l}\text { Quando está dirigindo, com que frequência cada uma destas } \\
\text { coisas acontece com você: }\end{array}$} \\
\hline & $\begin{array}{l}\text { Ao fazer fila para dobrar à esquerda em uma via } \\
\text { principal, você presta tanta atenção ao tráfego que } \\
\text { quase colide com o veículo à sua frente? }\end{array}$ & & & & & & \\
\hline & $\begin{array}{l}\text { Não percebe que pedestres estão atravessando } \\
\text { quando você dobra de uma avenida principal para } \\
\text { uma rua? }\end{array}$ & & & & & & \\
\hline & $\begin{array}{l}\text { Dirige tão perto do veículo à sua frente que seria } \\
\text { difícil parar em caso de emergência? }\end{array}$ & & & & & & \\
\hline & $\begin{array}{l}\text { Não percebe sinais "dê a preferência" e quase colide } \\
\text { com o tráfego que vem na preferência? }\end{array}$ & & & & & & \\
\hline & $\begin{array}{l}\text { Tenta ultrapassar alguém que você não percebeu que } \\
\text { estava sinalizando para dobrar à esquerda? }\end{array}$ & & & & & & \\
\hline & $\begin{array}{l}\text { Distraído ou preocupado, você demora a perceber } \\
\text { que o veículo na frente diminui a velocidade e você } \\
\text { tem de frear bruscamente para evitar uma colisão? }\end{array}$ & & & & & & \\
\hline & $\begin{array}{l}\text { Quando dirigindo na mesma velocidade que o } \\
\text { tráfego, você acha difícil parar a tempo quando o } \\
\text { sinal fecha para vocế? }\end{array}$ & & & & & & \\
\hline & $\begin{array}{l}\text { Entra em uma rua na frente de um veículo que você } \\
\text { não tinha notado ou cuja velocidade você tinha } \\
\text { calculado mal? }\end{array}$ & & & & & & \\
\hline 19. & $\begin{array}{l}\text { Não percebe um semáforo acionado por pedestres } \\
\text { que recém ficou vermelho para você? }\end{array}$ & & & & & & \\
\hline & $\begin{array}{l}\text { Não percebe alguém saindo de trás de um veículo } \\
\text { estacionado até que seja quase tarde demais? }\end{array}$ & & & & & & \\
\hline & $\begin{array}{l}\text { Dobra tão rápido em uma esquina que você sente } \\
\text { que pode perder o controle? }\end{array}$ & & & & & & \\
\hline & $\begin{array}{l}\text { Não percebe ou antecipa que o outro veículo pode } \\
\text { cortar a sua frente e então tem dificuldade de parar? }\end{array}$ & & & & & & \\
\hline 23. & Faz uma curva aberta quando dobra uma esquina? & & & & & & \\
\hline & $\begin{array}{l}\text { Quando abre o sinal, você acelera forte com a } \\
\text { intenção de deixar os outros motoristas para trás? }\end{array}$ & & & & & & \\
\hline & Dirige entre duas faixas de trânsito rápido & & & & & & \\
\hline & $\begin{array}{l}\text { Desrespeita o limite de velocidade tarde da noite ou } \\
\text { nas primeiras horas da manhã? }\end{array}$ & & & & & & \\
\hline & $\begin{array}{l}\text { Dirige quando você suspeita que pode estar acima } \\
\text { do limite legal de uso de álcool? }\end{array}$ & & & & & & \\
\hline
\end{tabular}




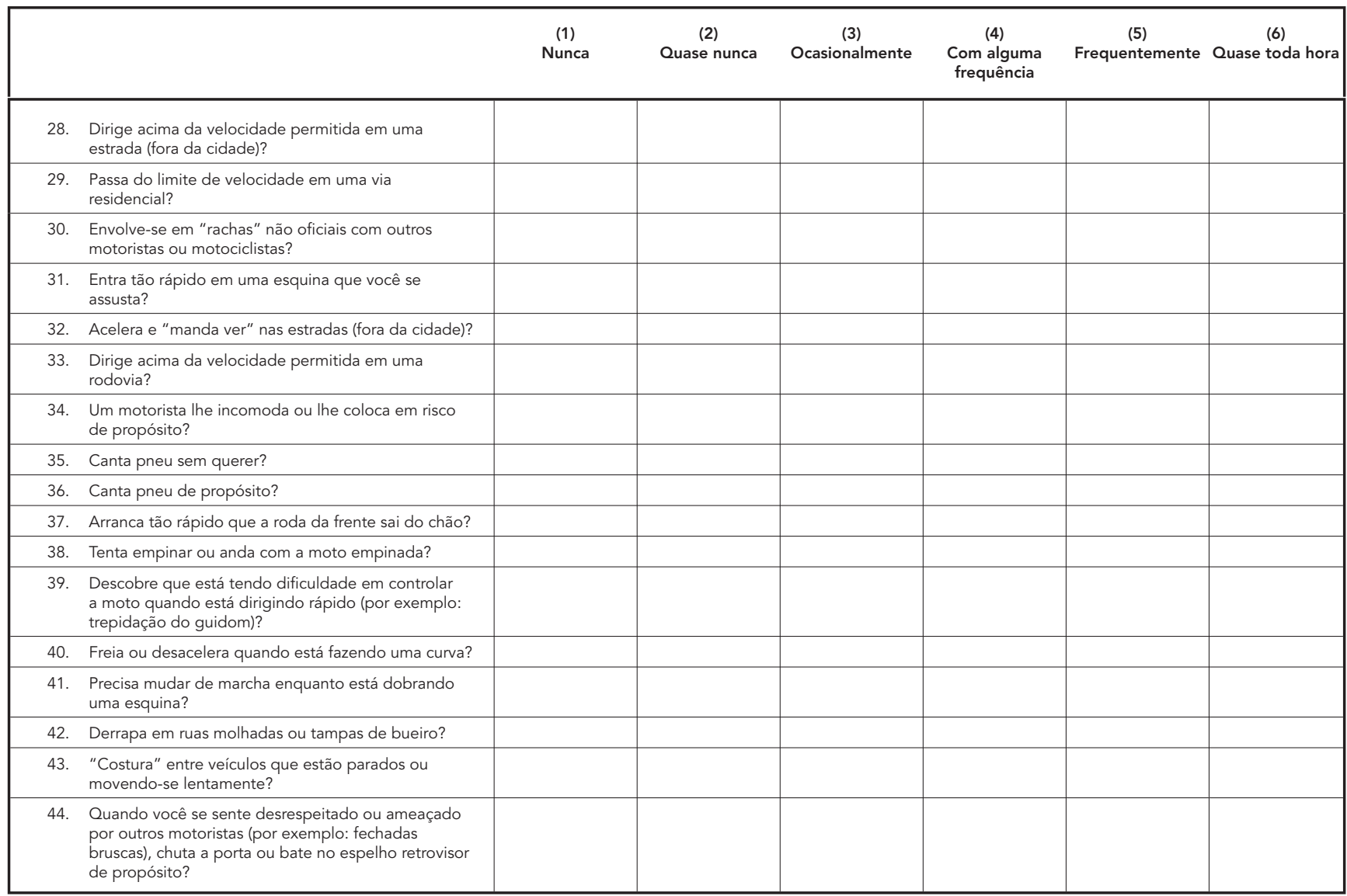

e heterogênea em futuros estudos, para certificar sua validade para outros grupos de motociclistas brasileiros.

De modo geral, os itens obtiveram boa equivalência entre as versões. A discussão acerca da apreciação da equivalência conceitual e de itens levou a ajustes linguísticos e adaptações termi- nológicas, proporcionando uma linguagem mais condizente com a utilizada pelos motociclistas. Na retrotradução para o inglês, a versão foi considerada fidedigna pelo autor da escala, formalizando assim a ECTM (Figura 1). Futuros estudos são necessários para avaliar as demais propriedades psicométricas da ECTM na nossa cultura. 


\section{Resumo}

Mundialmente os acidentes de trânsito aparecem como uma das principais causas de morte entre adultos jovens. No Brasil, os acidentes de trânsito são mais prevalentes em condutores de moto do que nos dos demais veículos. Não dispomos, no entanto, de instrumentos para avaliar o comportamento no trânsito em motociclistas. Temos o objetivo de traduzir e adaptar para o português brasileiro o instrumento Motorcycle Rider Behavior Questionnaire (MRBQ). O processo consistiu em: duas traduções independentes para o português; unificação das traduções, gerando a primeira versão; retrotradução para o inglês; apreciação formal de equivalência semântica, elaboração e aplicação em uma amostra de conveniência; discussão dos itens com problemas e elaboração de uma versão final; retrotradução desta e envio para o autor original, sendo aceita pelo mesmo. A versão brasileira do MRBQ conservou a equivalência semântica. O instrumento, de autopreenchimento, conservou suas propriedades, mostrandose de fácil entendimento para os motociclistas. Novos estudos são necessários para avaliar as propriedades psicométricas no nosso contexto.

Questionário; Tradução; Acidentes de Trânsito; Motocicletas

\section{Referências}

1. Scallan E, Staines A, Fitzpatrick P, Laffoy M, Kelly A. Unintentional injury in Ireland: a comparison of mortality and morbidity data. J Public Health (Oxf) 2004; 26:6-7.

2. World Health Organization. World report on road traffic injury prevention. Geneva:World Health Organization; 2004.

3. Elliot MA, Baughan CJ, Sexton BF. Errors and violations in relation to motorcyclists' crash risk. Accid Anal Prev 2007; 39:491-9.

4. Krug EG. Injury surveillance is key to preventing injuries. Lancet 2004; 364:1563-6.

5. Costa JSD, Victora CG. O que é "um problema de saúde pública”? Rev Bras Epidemiol 2006; 9:144-6.

6. Silva DW, Andrade SM, Soares DA, Soares DFPP, Mahias TAF. Perfil do trabalho e acidentes de trânsito entre motociclistas de entregas em dois municípios de médio porte do Estado do Paraná, Brasil. Cad Saúde Pública 2008; 24:2643-52.

\section{Colaboradores}

R. P. S. Coelho, A. V. Williams e M. Machado, B. C. Matte participaram da elaboração e redação do manuscrito. R. Grassi-Oliveira, L. A. P. Rohde, C. M. Szobot e F. Pechansky colaboraram na supervisão e revisão do manuscrito.

\section{Agradecimentos}

Este trabalho foi parcialmente financiado pela Secretaria Nacional de Políticas sobre Drogas (SENAD). Estendemos também nosso agradecimento à Indústria Farmacêutica Novartis.
7. Lin MR, Hwang HF, Kuo NW. Crash severity, injury patterns, and helmet use in adolescent motorcycle riders. J Trauma 2001; 50:24-30.

8. Herdman M, Fox-Rushby J, Badia X. A model of equivalence in the cultural adaptation of HRQoL instruments: the universalist approach. Qual Life Res 1998; 7:323-35.

9. Herdman M, Fox-Rushby J, Badia X. Equivalence and the translation and adaptation of health-related quality of life questionnaires. Qual Life Res 1997; 6:237-47.

10. Reason JT, Manstead ASR, Stradling SG, Baxter JS, Campbell K. Errors and violations on the road: a real distinction? Ergonomics 1990; 33:1315-32.

Recebido em 04/Ago/2011

Versão final reapresentada em 01/Fev/2012

Aprovado em 02/Mar/2012 